ARTICLE

httpst//doi.org/10.1038/s414.67-020-15167-2

\title{
Visible-light promoted regioselective amination and alkylation of remote $\mathrm{C}\left(\mathrm{sp}^{3}\right)-\mathrm{H}$ bonds
}

\author{
Quanping Guo', Qiang Peng ${ }^{1}$, Hongli Chai ${ }^{1}$, Yumei Huo ${ }^{1}$, Shan Wang ${ }^{1} \&$ Zhaoging Xu (D) ${ }^{1 凶}$
}

The C-N cross coupling reaction has always been a fundamental task in organic synthesis. However, the direct use of $\mathrm{N}-\mathrm{H}$ group of aryl amines to generate $\mathrm{N}$-centered radicals which would couple with alkyl radicals to construct $\mathrm{C}-\mathrm{N}$ bonds is still rare. Here we report a visible light-promoted $\mathrm{C}-\mathrm{N}$ radical cross coupling for regioselective amination of remote $\mathrm{C}\left(\mathrm{sp}^{3}\right)-\mathrm{H}$ bonds. Under visible light irradiation, the $\mathrm{N}-\mathrm{H}$ groups of aryl amines are converted to $\mathrm{N}$ centered radicals, and are then trapped by alkyl radicals, which are generated from HofmannLöffler-Freytag (HLF) type 1,5-hydrogen atom transfer (1,5-HAT). With the same strategy, the regioselective $\mathrm{C}\left(\mathrm{sp}^{3}\right)-\mathrm{C}\left(\mathrm{sp}^{3}\right)$ cross coupling is also realized by using alkyl Hantzsch esters (or nitrile) as radical alkylation reagents. Notably, the $\alpha-C\left(s p^{3}\right)-H$ of tertiary amines can be directly alkylated to form the $\mathrm{C}\left(\mathrm{sp}^{3}\right)-\mathrm{C}\left(\mathrm{sp}^{3}\right)$ bonds via $\mathrm{C}\left(\mathrm{sp}^{3}\right)-\mathrm{H}-\mathrm{C}\left(\mathrm{sp}^{3}\right)-\mathrm{H}$ cross coupling through the same photoredox pathway.

\footnotetext{
${ }^{1}$ Institute of Drug Design \& Synthesis, Institute of Pharmacology, Key Laboratory of Preclinical Study for New Drugs of Gansu Province, School of Basic Medical Science, Lanzhou University, 199 West Donggang Road, Lanzhou 730000, China. ${ }^{凶}$ email: zqxu@lzu.edu.cn
} 
A mines are quintessential moieties in pharmaceuticals, nature products, and organic materials ${ }^{1,2}$. In the past few decades, transition-metal-catalyzed $\mathrm{sp}^{2} \mathrm{C}-\mathrm{N}$ couplings of aryl halides (and pseudo halides) with amine nucleophiles have been well developed, such as Buchwald-Hartwig reaction ${ }^{3}$, Ullmann coupling 4 , and Chan-Lam amination ${ }^{5}$. However, the alkylation of amines using alkyl electrophiles is largely underdeveloped due to the $\beta$-hydrogen elimination from the metalalkyl intermediate ${ }^{6-8}$. Recently, significant progress has been made in transition-metal-catalyzed radical $\mathrm{sp}^{3} \mathrm{C}-\mathrm{N}$ bond formations. Fu and coworkers recently disclosed the photoinduced, $\mathrm{Cu}$-catalyzed intermolecular and intramolecular alkylation of amides ${ }^{9,10}$. Very recently, Macmillan ${ }^{11}$ and $\mathrm{Hu}^{12}$ reported a series of $\mathrm{Cu}$-catalyzed, photoinduced decarboxylative $\mathrm{sp}^{3} \mathrm{C}-\mathrm{N}$ coupling reactions, respectively. In these approaches, the trapping of alkyl radicals by $\mathrm{Cu}$-amine species and the reductive eliminations of $\mathrm{Cu}$ intermediates were key steps for the cross-couplings (Fig. 1a).

In the past few years, the addition reactions of $\mathrm{N}$-center radical to alkenes (or enamine intermediates) have been developed (Fig. 1b $)^{13-20}$. However, the direct cross-coupling between alkyland $\mathrm{N}$-based radicals in the absence of stabilization by transitionmetal complex has been rarely explored. Moreover, in the reactions, the amine (or amide) compounds need to be converted to the corresponding $\mathrm{N}$-radical precursors (e.g., N-halogens and Nnitrosoamides) by separated steps. The direct use of the $\mathrm{N}-\mathrm{H}$ group of aryl amines to generate $\mathrm{N}_{\text {aryl }}$-center radicals and couple with alkyl radicals is still rare ${ }^{17}$.

The regioselective $\mathrm{C}-\mathrm{H}$ functionalization is one of the most fundamental reactions in organic synthetic chemistry. In recent years, the functionalization of $\mathrm{C}\left(\mathrm{sp}^{3}\right)-\mathrm{H}$ bonds has become an important and intensive task to the organic synthetic community. In the past decade, great progress has been achieved in $\mathrm{C}\left(\mathrm{sp}^{3}\right)-\mathrm{H}$ functionalization at unactivated sites, which allows streamlined synthesis of target compounds and late-stage modification of complex structures. Recently, the application of HofmannLöffler-Freytag (HLF)-type 1,5-hydrogen atom transfer (1,5-HAT) in $\mathrm{C}\left(\mathrm{sp}^{3}\right)-\mathrm{H}$ functionalization reactions received much attention due to their unique regioselectivities ${ }^{21,22}$. Although the amidyl radical formation and its subsequent 1,5 -HAT process have been well established, the followed transformations of the C-center radical are still limited, and the reactions mainly focused on cyclization $^{23-29}$, atom transfer (halogenation) ${ }^{30-33}$, Giese reaction $^{34-37}$, azidation ${ }^{38,39}$, cyanation ${ }^{40,41}$, trifluoromethylation ${ }^{42}$, and

a

$$
\cdot R+\operatorname{CuNR} R^{2} \stackrel{S E T}{\longrightarrow} R C u N R^{1} R^{2} \stackrel{\text { reductive elimination }}{\longrightarrow} R-N R^{1} R^{2}
$$

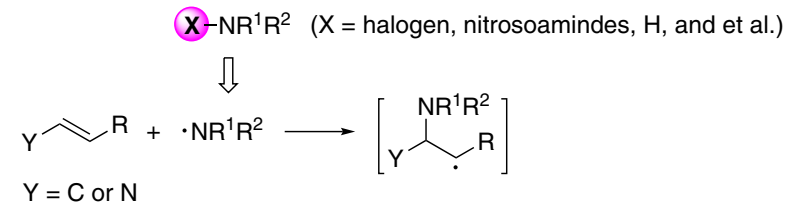$$
\text { b }
$$

arylation $)^{43,44}$. So far, using the HLF-type C-center radical for $\mathrm{sp}^{3}$ $\mathrm{C}-\mathrm{N}$ or $\mathrm{C}\left(\mathrm{sp}^{3}\right)-\mathrm{C}\left(\mathrm{sp}^{3}\right)$ couplings is still very rare $\mathrm{r}^{45}$, and the direct cross-coupling between $\mathrm{C}\left(\mathrm{sp}^{3}\right)-\mathrm{H}$ and $\mathrm{N}-\mathrm{H}$ is not realized. We here report an example of $\mathrm{sp}^{3} \mathrm{C}-\mathrm{N}$ cross-coupling reaction between $\mathrm{N}$-center- and alkyl radicals. Notably, the aryl amines are directly converted to $\mathrm{N}$-center radicals under visible-light irradiation (Fig. 1c). By using the same photoredox catalytic 1,5-HAT strategy, the regioselective $\mathrm{C}\left(\mathrm{sp}^{3}\right)-\mathrm{H}$ alkylation can also be realized when Hantzsch esters are used as alkylation reagents. The primary, secondary, and tertiary alkylation are all compatible under standard conditions. It is worth noting that the $\mathrm{a}-\mathrm{C}\left(\mathrm{sp}^{3}\right)-\mathrm{H}$ of tertiary amines can be directly alkylated to form $\mathrm{C}\left(\mathrm{sp}^{3}\right)-\mathrm{C}\left(\mathrm{sp}^{3}\right)$ bonds without pre-functionalization.

\section{Results}

Investigation of the $\mathrm{sp}^{3} \mathrm{C}-\mathrm{N}$ coupling reaction conditions. The investigation was initiated by using $\mathrm{N}$-(tert-butyl)- $\mathrm{N}$-fluoro-2methylbenzamide (1a) and aniline (2a) as model substrates. A series of photocatalysts (Ir and Ru complexes, or organic photocatalysts), light sources, solvents, additives, and the substrate ratios were tested (see the Supplementary Information for details). The results indicated the optimal reaction conditions (condition $\mathrm{A}$ ): under 24-W violet LED (390-410 nm) irradiation, 1a and 2a (3 equiv) were dissolved in $\operatorname{DMF}(0.1 \mathrm{M}), \operatorname{Ir}(\mathrm{ppy})_{2}(\mathrm{dtbpy}) \mathrm{PF}_{6}$ ( $1 \mathrm{~mol} \%)$ was used as the photocatalyst, $\mathrm{K}_{2} \mathrm{CO}_{3}$ (3.0 equiv) was used as basic additive, and the reaction was stirred at room temperature for $12 \mathrm{~h}$. Under these reaction conditions, the desired $\mathrm{sp}^{3} \mathrm{C}-\mathrm{N}$ coupling product (3a) was isolated in $73 \%$ yield. Notably, to achieve this transformation, a suitable photocatalyst with wellbalanced redox potential was required. The organic photocatalysts A-D have relatively strong oxidative properties, whereas the reductive activities were moderate. In contrast, the $\mathrm{Ir}-$ and $\mathrm{Ru}$ based photocatalysts have good redox abilities, which were compatible for the reaction (Table 1).

Scope of $\mathbf{s p}^{3} \mathbf{C}-\mathbf{N}$ coupling reactions. With the optimal reaction conditions in hand, the substrate scope of carboxylamides and anilines was examined, and the results are summarized in Fig. 2. To our delight, the carboxamides and anilines bearing electron-donating and electron-withdrawing groups at $o^{-}, m^{-}$, or $p$-position of the aryl ring were compatible with moderate-to-good yields (Fig. 2, 3a-3x). A range of functional groups, such as $-\mathrm{CH}_{3}$, b

C

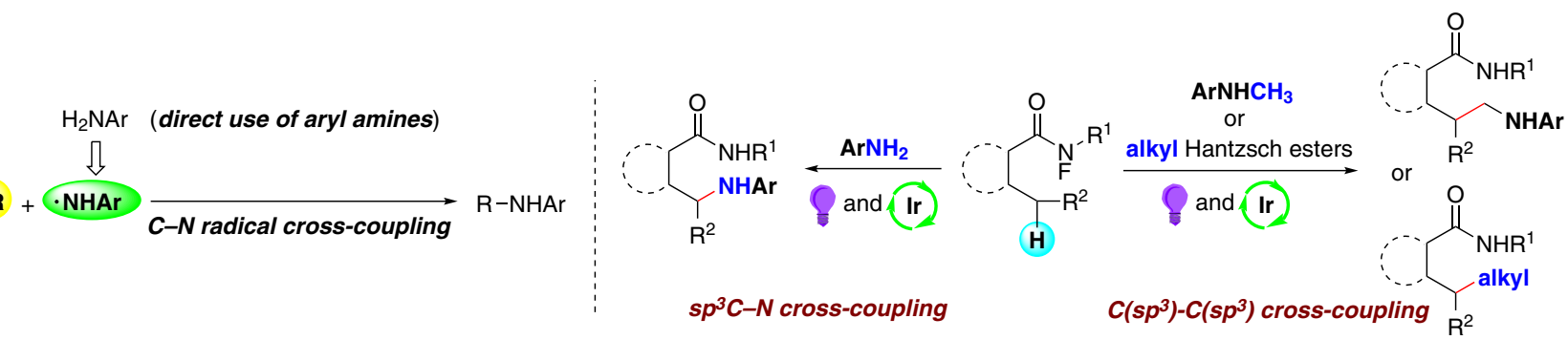

Fig. 1 sp $^{3}$ C-N bond formations with $\mathbf{N}$-center radicals. a Cu-catalyzed radical sp ${ }^{3} \mathrm{C}-\mathrm{N}$ cross-couplings ${ }^{6-8}$. b Addition reactions between $\mathrm{N}$-center radicals and alkenes (enamines) ${ }^{9}$. c This work: $\mathrm{sp}^{3} \mathrm{C}-\mathrm{N}$ cross-coupling between alkyl radical and $\mathrm{N}$-center radical. $\mathrm{X}=$ halogen, nitrosoamides, $\mathrm{H}$, and so on. $\mathrm{Y}=\mathrm{C}$ or $\mathrm{N}$. 
Table 1 Optimization of reaction conditions ${ }^{\mathrm{a}}$.

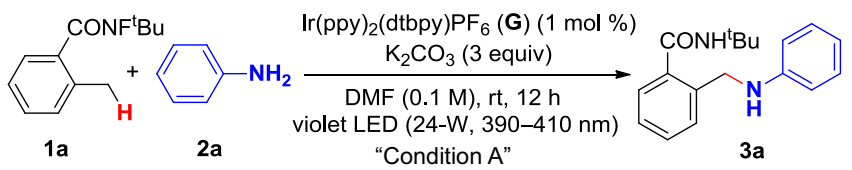

\begin{tabular}{ll}
\hline Entry & Change to "condition A" \\
\hline 1 & Condition $\mathrm{A}$ \\
2 & No light \\
3 & No photocatalyst \\
4 & Without $\mathrm{K}_{2} \mathrm{CO}_{3}$ \\
5 & $\mathrm{~A}, \mathrm{~B}, \mathrm{C}, \mathrm{D}$ instead of $\mathrm{G}$ \\
6 & $\mathrm{E}, \mathrm{F}, \mathrm{H}$ instead of $\mathrm{G}$ \\
7 & Other bases instead of $\mathrm{K}_{2} \mathrm{CO}_{3}$ \\
8 & Other solvents instead of $\mathrm{DMF}$
\end{tabular}

a Unless noted, the reactions were carried out using $\mathbf{1 a}(0.1 \mathrm{mmol}), \mathbf{2 a}$ ( 3 equiv), photocatalyst ( $1 \mathrm{~mol} \%$ ), base ( 3.0 equiv), and DMF ( $\mathrm{ml})$, under Ar, and stirred at $\mathrm{rt}$ for $12 \mathrm{~h}$ under $24-\mathrm{W}$ violet $\mathrm{LED}$ irradiation.

blsolated yields.
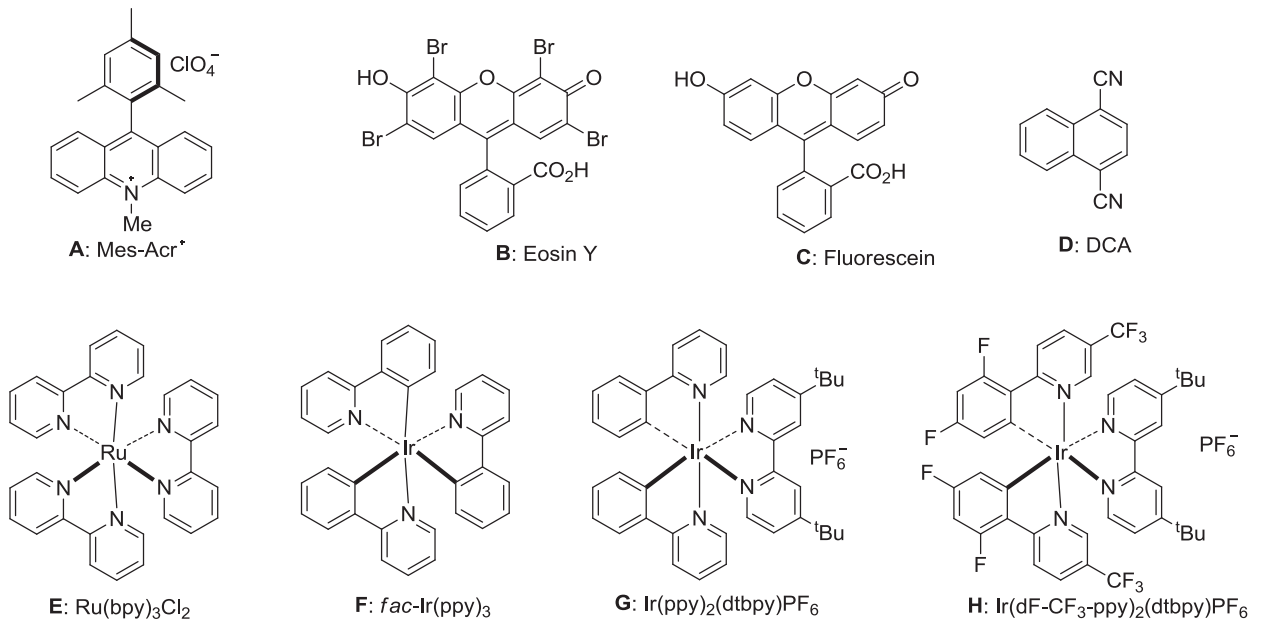

$-\mathrm{OCH}_{3},-\mathrm{CF}_{3}$, and halides $(-\mathrm{F},-\mathrm{Cl}$, and $-\mathrm{Br})$ were all tolerated. The bulkier amines, such as EtNHPh and i-PrNHPh, were successfully converted to the corresponding products $\mathbf{3} \mathbf{w}$ and $\mathbf{3 x}$ with satisfactory yields, respectively. Notably, the amination of alkyl amide was also achieved under standard conditions (3y). However, the alkyl-substituted amines, such as $\mathrm{CyNH}_{2}$ and $\mathrm{n}-\mathrm{Bu}_{2} \mathrm{NH}$, failed to give the corresponding amination products.

Alkylation of tertiary amine $\boldsymbol{\alpha}-\mathrm{C}\left(\mathrm{sp}^{3}\right)-\mathbf{H}$ bonds. Tertiary amine motifs are widely represented in many pharmaceuticals and advanced materials ${ }^{1,2}$. Direct functionalization of tertiary amine provides an efficient pathway to synthesize structurally diversified tertiary amines. In 2006, $\mathrm{Li}$ and coworkers reported a crossdehydrogenative-coupling reaction, which could directly couple the $\alpha-C(s p)^{3}-\mathrm{H}$ of tertiary amines with nucleophiles under oxidative conditions ${ }^{46-49}$. Very recently, the photoredox-induced $\alpha-C$ $(\mathrm{sp})^{3}-\mathrm{H}$ functionalization of tertiary amines was achieved, which could functionalize the $\alpha-\mathrm{C}(\mathrm{sp})^{3}-\mathrm{H}$ under mild and external oxidant-free conditions ${ }^{50,51}$. Despite these achievements, the direct $\mathrm{C}\left(\mathrm{sp}^{3}\right)-\mathrm{C}\left(\mathrm{sp}^{3}\right)$ cross-coupling reactions between tertiary amines $\alpha$ $\mathrm{C}\left(\mathrm{sp}^{3}\right)-\mathrm{H}$ and unactivated $\mathrm{C}\left(\mathrm{sp}^{3}\right)-\mathrm{H}$ were still not realized.

Encouraged by the success of photoredox $\mathrm{sp}^{3} \mathrm{C}-\mathrm{N}$ coupling, we decided to explore an alternate route to realize regioselective $\mathrm{C}$ $\left(\mathrm{sp}^{3}\right)-\mathrm{C}\left(\mathrm{sp}^{3}\right)$ coupling between tertiary amines $\mathrm{a}-\mathrm{C}\left(\mathrm{sp}^{3}\right)-\mathrm{H}$ and unactivated $\mathrm{C}\left(\mathrm{sp}^{3}\right)-\mathrm{H}$ using the photoredox 1,5-HAT strategy. In our initial hypothesis, upon irradiation, the high valent photocatalyst could accept an electron from amine and simultaneously generate an amino radical cation $\mathbf{A}$ through single-electron transfer (SET) process (Fig. 3). The amino radical cation would then form a-amino alkyl radical $\mathbf{B}$ by deprotonation. The intermediate $\mathbf{B}$ could be captured by $\mathrm{C}$-center radical $\mathbf{D}$ that was generated through $1,5-\mathrm{HAT}$, and furnished the $\mathrm{C}\left(\mathrm{sp}^{3}\right)-\mathrm{C}\left(\mathrm{sp}^{3}\right)$ coupling.

Scope of alkylation of tertiary amine $\alpha-C\left(\mathrm{sp}^{3}\right)-\mathrm{H}$ bonds. With the above hypothesis in mind, we began our study by using $\mathbf{1 a}$ and $\mathrm{N}, \mathrm{N}$-dimethylaniline (2a') as model substrates to optimize the reaction conditions (see the Supplementary Information for details). Under the optimal conditions (condition A), the desired $\mathrm{C}\left(\mathrm{sp}^{3}\right)-\mathrm{C}$ $\left(\mathrm{sp}^{3}\right)$ cross-coupling product $(\mathbf{4 a})$ was obtained in $75 \%$ yield. The generality of the reaction was examined by using a variety of tertiary amines and carboxamides (Fig. 4, 4a-4o). To our delight, uniformly good results were obtained with various substrates bearing sensitive functional groups. The $\mathrm{C}-\mathrm{H}$ functionalization of alkyl amide was also realized with good yield (5). Furthermore, the late-stage modification of androsterone-derived amine was achieved in $56 \%$ yield with the ester group untouched $\mathbf{6}$.

$\mathrm{C}\left(\mathrm{sp}^{3}\right)-\mathrm{C}\left(\mathrm{sp}^{3}\right)$ coupling reaction using alkyl Hantzsch ester. In the past few years, the HLF-type radical cross-coupling reactions 


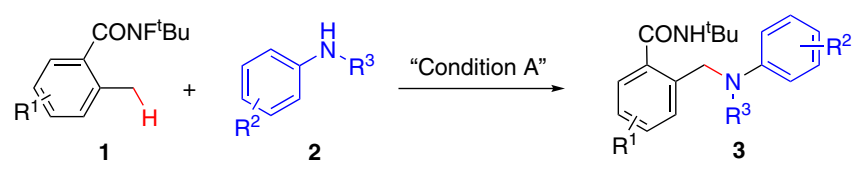<smiles>CCOC(=O)c1ccccc1CNc1ccccc1</smiles>

3a, $73 \%$<smiles>CCCCNc1ccc(OC)cc1</smiles>

3g, $40 \%$<smiles>CCCCNc1c(Cl)cccc1C(=O)OCc1ccccc1</smiles>

3b, $69 \%$<smiles>CCCCCNc1cc(C)cc(C)c1</smiles>

3h, $64 \%$<smiles>CCCCNc1ccccc1CNc1c(C)cccc1C(=O)OCC</smiles>

3c, $65 \%$<smiles>CCCCNc1ccccc1CNc1ccc(Br)cc1C(=O)OC</smiles>

3d, $67 \%$<smiles>CCCc1ccc(C(=O)OC)c(CNc2ccccc2)c1</smiles>

3e, $75 \%$<smiles>CCCCNc1ccccc1CNc1cc(C(F)(F)F)ccc1C(=O)OCC</smiles><smiles>CCCCCNc1ccc(F)cc1CNc1ccccc1C(=O)OCC</smiles>

$3 \mathbf{3 i}, 63 \%$<smiles>CCCCNc1ccc(C(F)(F)F)cc1</smiles>

$3 \mathbf{3}, 66 \%$<smiles>CCCCCNc1cccc2cccnc12</smiles>

3k, $57 \%$ yield

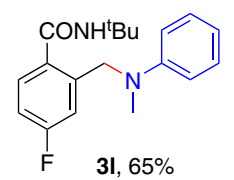

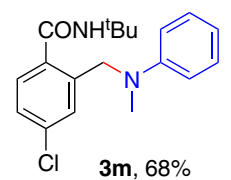<smiles>CCCCN(Cc1ccccc1C(=O)OCC)c1ccccc1</smiles>

3n, $61 \%$<smiles>CCCCOC(=O)c1ccc(Br)cc1CN(C)c1ccccc1</smiles>

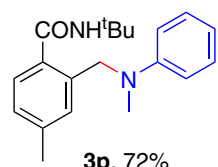<smiles>CCCCCN(C)c1ccc(C)cc1C(=O)N(C)c1ccccc1</smiles>

$3 q, 74 \%$<smiles>CCCCN(C)c1ccccc1C(=O)OCCCC(C)(C)C</smiles>

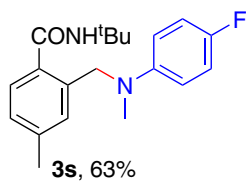<smiles>CCCCN(Cc1ccccc1C(=O)OC)c1ccc(C(F)(F)F)cc1</smiles>

3t, $69 \%$<smiles>CCCCCN(C)c1ccc(C)cc1CN(C)c1ccccc1C(=O)OCC</smiles>

3u, $64 \%$<smiles>CCCCN(Cc1cc(C)ccc1C(C)=O)c1ccccc1</smiles><smiles>CCOC(=O)c1ccccc1CN(CC)c1ccccc1</smiles><smiles>CCCCN(Cc1ccccc1C(=O)OCC)c1ccccc1</smiles>

3w, $57 \%$

Amination of alkyl amide:<smiles>CC(C)CCCC(C)(C)NC(=O)c1ccccc1</smiles>

10<smiles>CC(C)C(CCC(C)(C)NC(=O)c1ccccc1)Nc1ccc(C(F)(F)F)cc1</smiles>

Fig. 2 Substrate scope of $\mathbf{s p}^{3} \mathbf{C}-\mathbf{N}$ coupling reactions. All reactions were conducted in $0.2 \mathrm{mmol}$ scale. Yields referred to isolated yields.

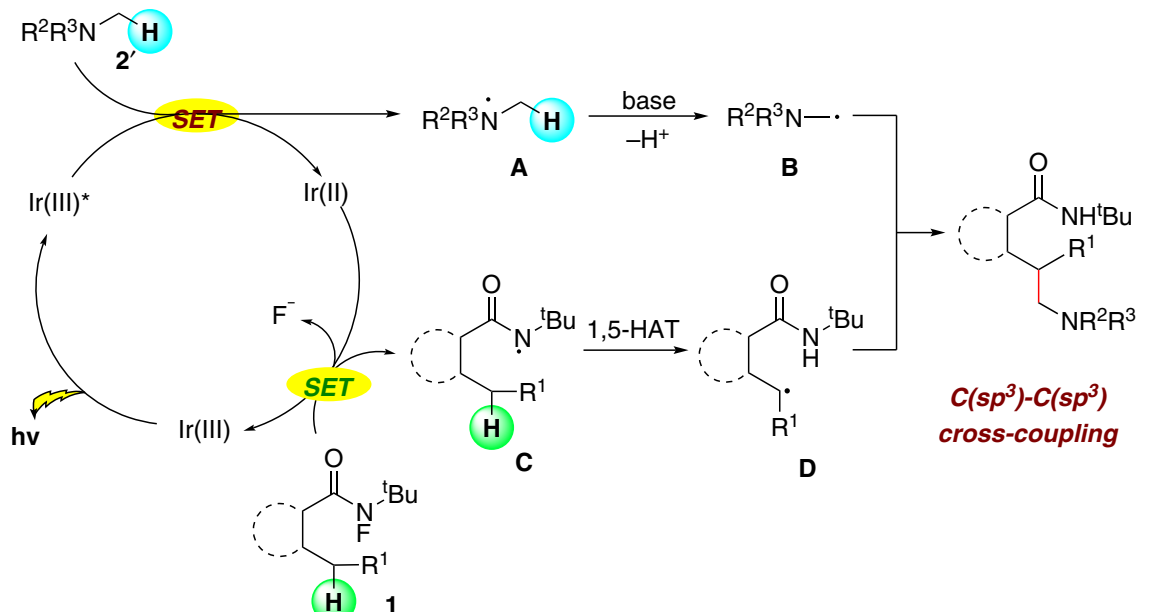

Fig. 3 Design plan for alkylation of tertiary amine $\boldsymbol{\alpha}-\mathbf{C}\left(\mathbf{s p}^{\mathbf{3}}\right)-\mathbf{H}$ bonds. Hypothesis of the mechanism for photoinduced $C\left(\mathrm{sp}^{3}\right)-\mathrm{C}\left(\mathrm{sp}^{3}\right) \operatorname{coupling}$ reactions.

were intensively studied ${ }^{21-44}$. However, its application in the construction of $\mathrm{C}\left(\mathrm{sp}^{3}\right)-\mathrm{C}\left(\mathrm{sp}^{3}\right)$ was still rare ${ }^{45}$. Hantzsch esters were first synthesized by A. R. Hantzsch in 1881, and widely used in pharmaceutical chemistry. With the rapid development of radical chemistry, various alkylation reactions using 4-substituted Hantzsch esters as alkylation reagent have been developed ${ }^{52-55}$. However, the cross-coupling between alkyl Hantzsch esters and C $\left(\mathrm{sp}^{3}\right)-\mathrm{H}$ was still not realized.
In the above successful $\mathrm{C}\left(\mathrm{sp}^{3}\right)-\mathrm{H}$ alkylation reactions (Fig. 4), the alkyl radicals were generated through 1,2-SET of $\mathrm{N}$-center radical, which restricted the scope of alkyl substrates. Alkyl Hantzsch ester has the ability to serve both as a singleelectron reductant and alkyl radical precursor. We envisioned that alkyl Hantzsch esters could be used instead of tertiary amine as the alkylation reagents for the direct $\mathrm{C}\left(\mathrm{sp}^{3}\right)-\mathrm{C}\left(\mathrm{sp}^{3}\right)$ cross-coupling. 


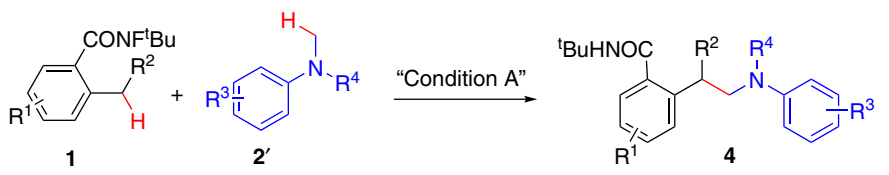

(n)

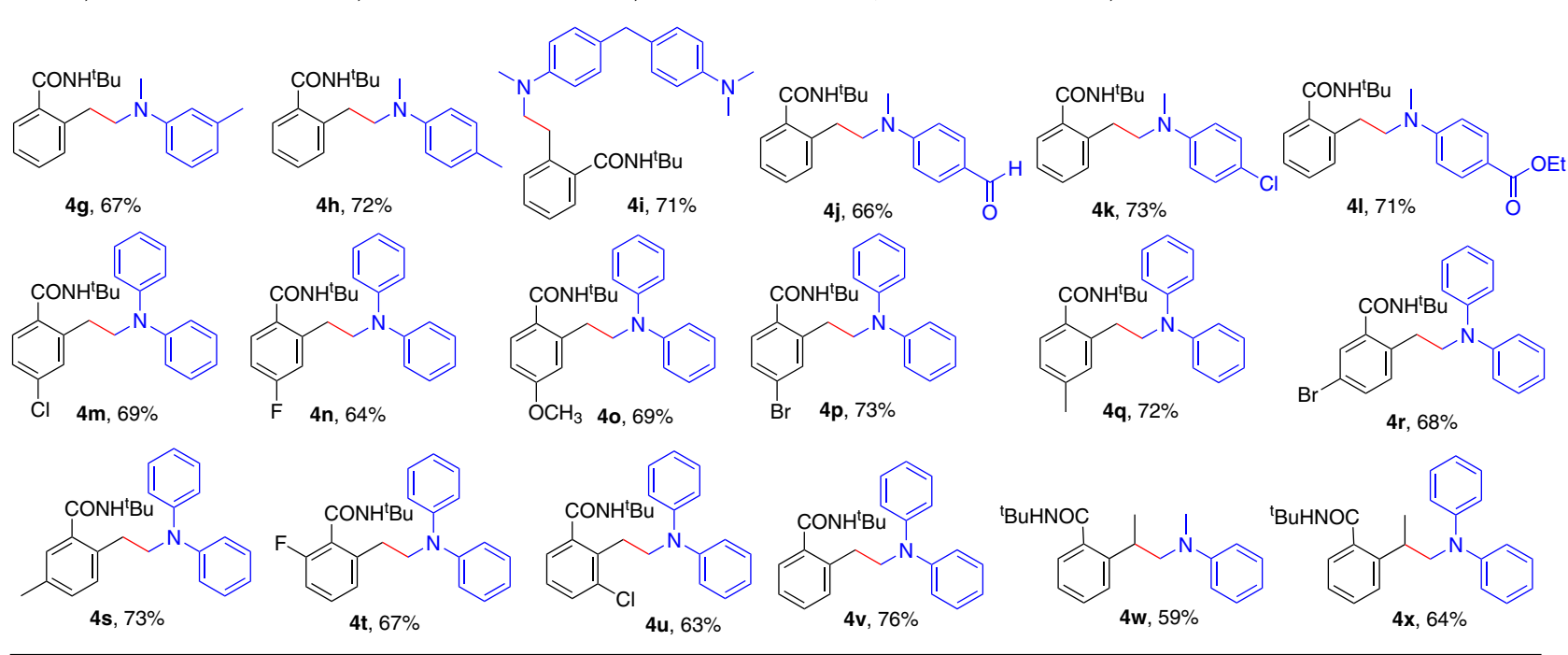

C-H alkylation of alkyl amide:

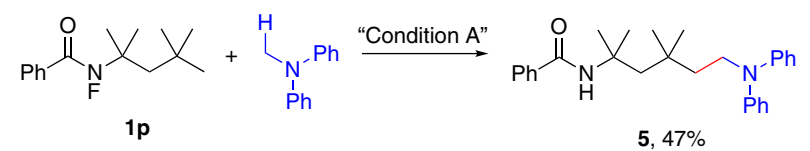

$5,47 \%$

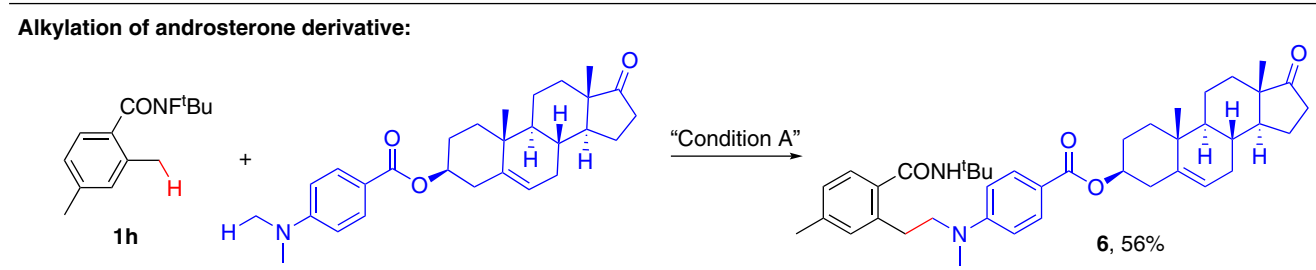

Fig. 4 Substrate scope of alkylation of tertiary amine $\boldsymbol{\alpha}-\mathbf{C}\left(\mathbf{s p}^{\mathbf{3}}\right)$-H bonds. All reactions were conducted in $0.2 \mathrm{mmol}$ scale. Yields referred to isolated yields.

Scope of $\mathbf{C}\left(\mathbf{s p}^{3}\right)-\mathbf{C}\left(\mathbf{s p}^{3}\right)$ coupling. Initially, cyclohexyl Hantzsch ester (7a) was used as model substrate to optimize the reaction conditions. After the screening of reaction parameters, the desired $\mathrm{C}\left(\mathrm{sp}^{3}\right)-\mathrm{C}\left(\mathrm{sp}^{3}\right)$ cross-coupling product $(\mathbf{8 a})$ could be obtained in $71 \%$ yield (condition B, see the Supplementary Information for details). Then, the substrate scope of carboxylamides was examined (Fig. 5). To our delight, the carboxamides bearing electrondonating and electron-withdrawing groups at $o-, m$-, or $p$-position of the aryl ring were compatible with moderate-to-good yields $(\mathbf{8 a}-\mathbf{8 1})$. A range of functional groups, such as $-\mathrm{CH}_{3}$, $-\mathrm{OCH}_{3}$, and halides $(-\mathrm{F},-\mathrm{Cl}$, and $-\mathrm{Br})$, were all tolerated $(\mathbf{8 a}-$ $\mathbf{8 k})$. The thiophene-derived substrate delivered the desired product with $72 \%$ yield (81). The regioisomers were found in the case of $8 \mathrm{~m}$, which might be attributed to the competing 1,6-HAT pathway ${ }^{32,56}$

To further explore the substrate scope, a variety of alkyl Hantzsch esters were examined (Fig. 6). To our delight, the primary and the secondary alkyl Hantzsch esters, as well as the tertiary alkyl Hantzsch nitrile, all proceeded smoothly in satisfactory results $(\mathbf{9 a}-\mathbf{1 1} \mathbf{b})$ with the sensitive functional groups (halogens and alkenes) untouched. The results indicated the general ability of our strategy for the construction of $\mathrm{C}\left(\mathrm{sp}^{3}\right)-\mathrm{C}$ $\left(\mathrm{sp}^{3}\right)$ bonds in the synthetic chemistry. Notably, the aryl Hantzsch esters failed to give any desired products under our standard conditions. It should be noted that our method was suitable not only for $o$-methylbenzamide, but also alkyl amide. As shown in Fig. 6, under the standard reaction conditions, 10 and $1 \mathbf{p}$ were smoothly coupled with alkyl Hantzsch esters in satisfactory yields (12a-12d).

Synthetic applications. To demonstrate the synthetic application of our method, the amination and alkylation products were readily converted to the corresponding lactam (3f') and acid (4s' and 10b') through simple operations with excellent yields, respectively (Fig. 7). 


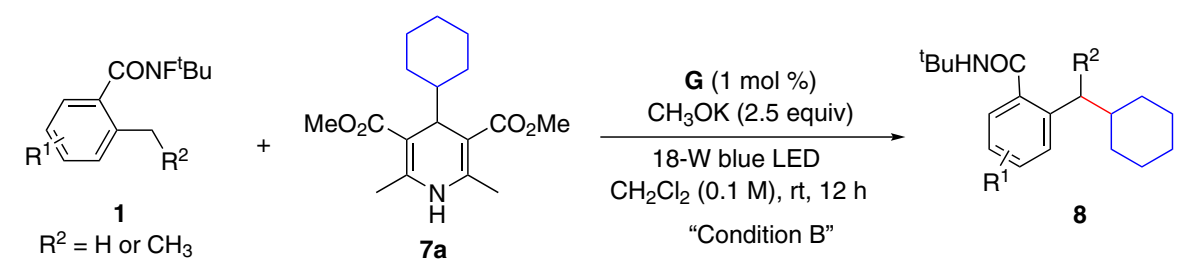

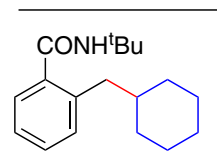

8 a, $71 \%$

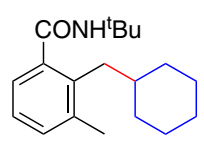

$8 b, 56 \%$

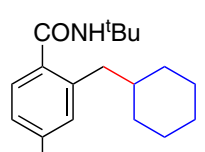

$8 c, 63 \%$

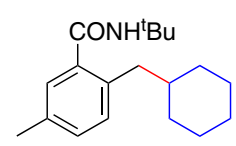

$8 d, 67 \%$

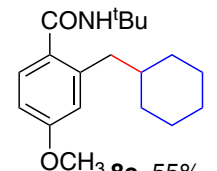

$8 e, 55 \%$

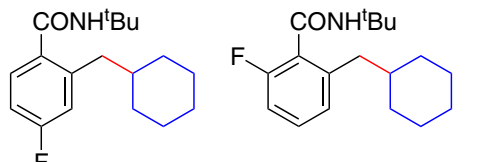

$8 f, 73 \%$

$8 g, 69 \%$<smiles>CCCCCCCCC(C)(C)C</smiles>

$8 h, 65 \%$

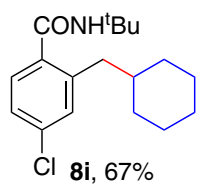<smiles>CCCCCCCc1cccc(Cl)c1C(=O)O</smiles>

8j, $59 \%$<smiles>CCCCCCNC(=O)c1ccc(C)cc1CC1CCCCC1</smiles>

$\mathrm{Br} \mathbf{8 k}, 70 \%$

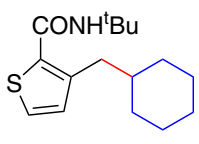

8I, $72 \%$

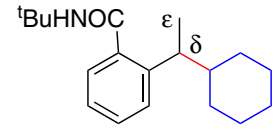

$8 \mathrm{~m}, 45 \%(\delta: \varepsilon=3: 1)$

Fig. 5 Substrate scope of carboxylamides with cyclohexyl Hantzsch ester. All reactions were conducted in 0.2 mmol scale. Yields referred to isolated yields.
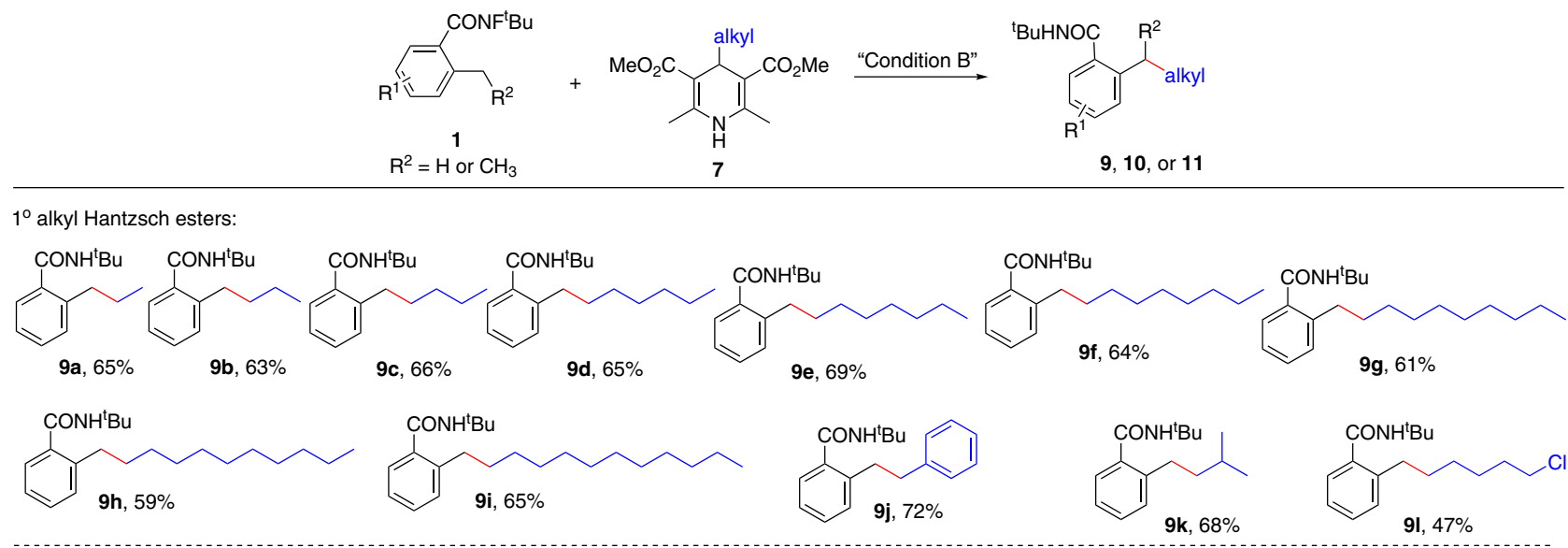

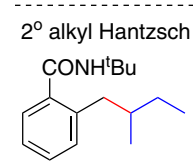

10a, $70 \%$<smiles>CCCCCCC(CC)Cc1ccccc1C(=O)OC</smiles>

10b, $75 \%$

$10 i, 73 \%$

10h, $69 \%$<smiles>CCCCNC(=O)c1cc(Br)ccc1C(C)Cc1c(CC(C)c2cccc(C(C)Cc3c(OC)cccc3C(=O)NCCCC)c2CC(C)c2ccccc2)cccc1C(=O)NCCCC</smiles>

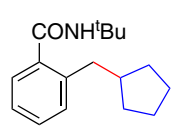

10c, $67 \%$

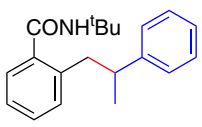

10d, $74 \%$<smiles>CCCCCCCC(=O)c1ccccc1CC1CC=CCC1</smiles>

10 e, $68 \%$<smiles>CCCCNC(=O)c1ccccc1CC(C)CCC=C(C)C</smiles>

10f, $72 \%$

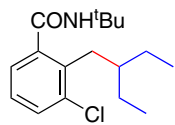

10g, $71 \%$

10j, $65 \%$

$10 k, 55 \%$

10I, $74 \%$

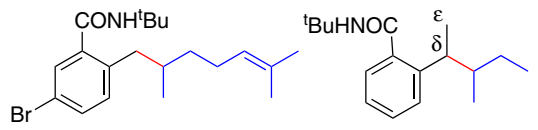

$3^{\circ}$ alkyl Hantzsch nitrile:<smiles>CCCCC(C)(C)Cc1ccccc1C(=O)OCC</smiles><smiles>CCCCC(C)(C)Cc1c(Cl)cccc1C(=O)OCC</smiles>

11a, $52 \%$

11b, $43 \%$

\section{C-H alkylation of alkyl amides (under condition B):}<smiles>CC(C)C(CCC(C)(C)NC(=O)Nc1ccccc1)C1CCCCC1</smiles>

12a, $64 \%$<smiles>CCCCCCCC(CCC(C)(C)NC(=O)c1ccccc1)C(C)C</smiles>
12b, $56 \%$

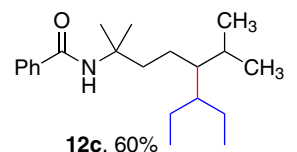<smiles>CC(C)(CCc1ccccc1)CC(C)(C)NC(=O)c1ccccc1</smiles>

$12 d, 53 \%$

Fig. 6 Substrate scope of alkyl Hantzsch esters and nitrile. All reactions were conducted in $0.2 \mathrm{mmol}$ scale. Yields referred to isolated yields. 
(1)

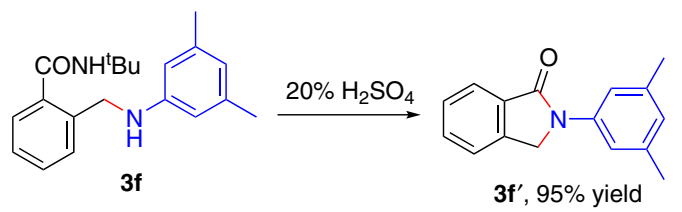

(2)<smiles>CCCCN(CCc1ccc(C)cc1C(=O)OCC)c1ccccc1</smiles>

$4 \mathrm{~s}$<smiles>O=S1(=O)OCCSO1</smiles><smiles>CC=CC=C(C)C</smiles>

(3)

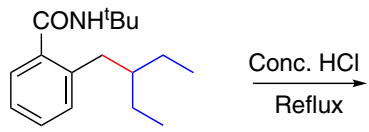

$10 \mathrm{~b}$<smiles>CCC(CC)Cc1ccccc1C(=O)O</smiles>

$10 b^{\prime}, 98 \%$ yield

Fig. 7 Synthetic applications. (1) Synthesis of lactam 3f'. (2) and (3) Converted amides to acids.<smiles>Cc1ccccc1C(=O)OCc1ccccc1</smiles><smiles>Nc1ccccc1</smiles>

2a

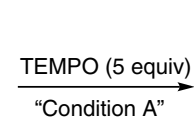<smiles>NC(=O)c1ccccc1CNc1ccccc1</smiles>

3a, $0 \%$

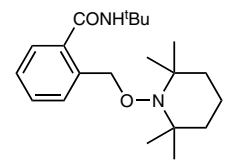

Detected by HRMS

(2):

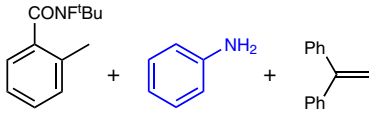
"Condition A"<smiles>Nc1ccccc1CCC(Nc1ccccc1)(c1ccccc1)c1ccccc1</smiles>

$1 a$

2a

(3 equiv)

$13,45 \%$

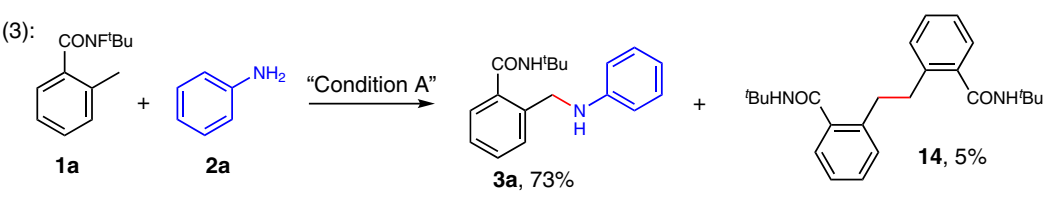<smiles>CC(=O)c1ccccc1C</smiles>

15<smiles>Nc1ccccc1</smiles>

2a

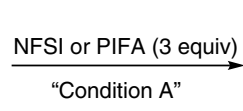

"Condition A"<smiles>CC(=O)c1ccccc1CNc1ccccc1</smiles>

3a, not detected

(5):<smiles>CC(C)(C)c1ccccc1C(=O)Nc1ccccc1</smiles>

$2 a$<smiles>CC(=O)c1ccccc1CNc1ccccc1</smiles>

$3 a, 53 \%$

(6):

a

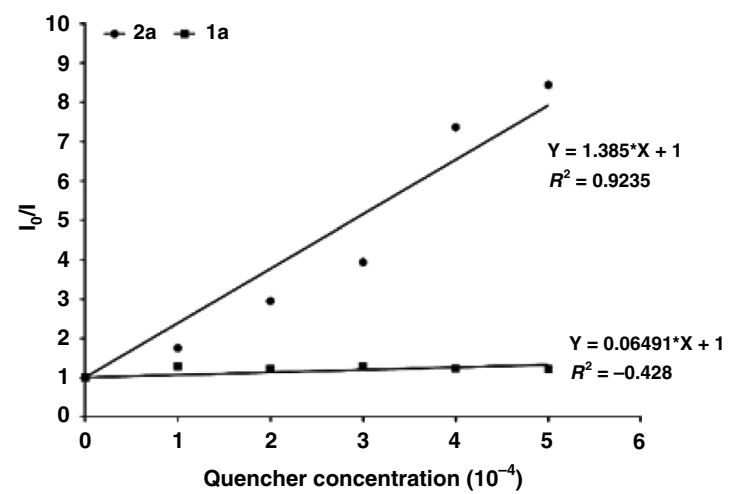

b

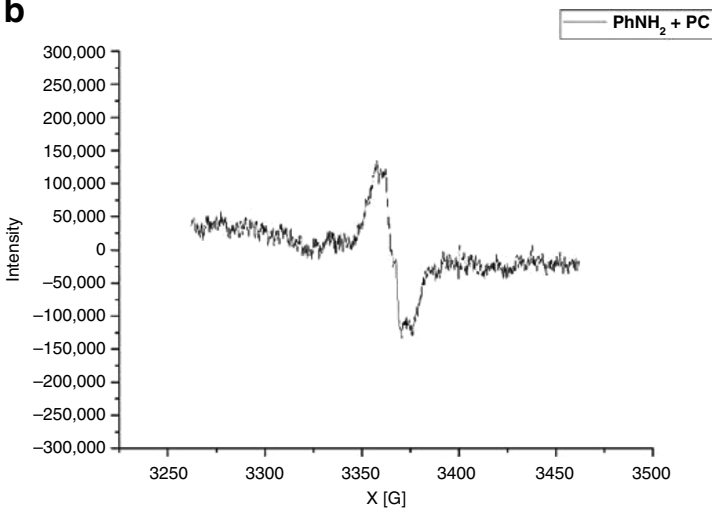

Fig. 8 Mechanistic studies. Equation (1) Radical trapping reaction with TEMPO. (2) Radical trapping reaction with ethane-1,1-diyldibenzene. (3) Homocoupling product. (4) The results under oxidative conditions. (5) The result with $\mathrm{N}$-chloroamide substrate. (6) (a) Fluorescence quenching of Ir (ppy) $)_{2}$ (dtbpy)PF 6 by $\mathbf{2 a}$ and $\mathbf{1 a}$. (b) EPR experiment result of $\mathrm{PhNH}_{2}$ (2a, $\mathrm{PhNH}_{2}(0.1 \mathrm{mmol})$ and $\operatorname{Ir}(\mathrm{ppy})_{2}$ (dtbpy) PF 6 (5 mol\%) in hexafluoroisopropanol $(1 \mathrm{ml})$, stirred at room temperature for $1 \mathrm{~h}$ under $400-\mathrm{nm}$ irradiation, and directly used for EPR experiments). 


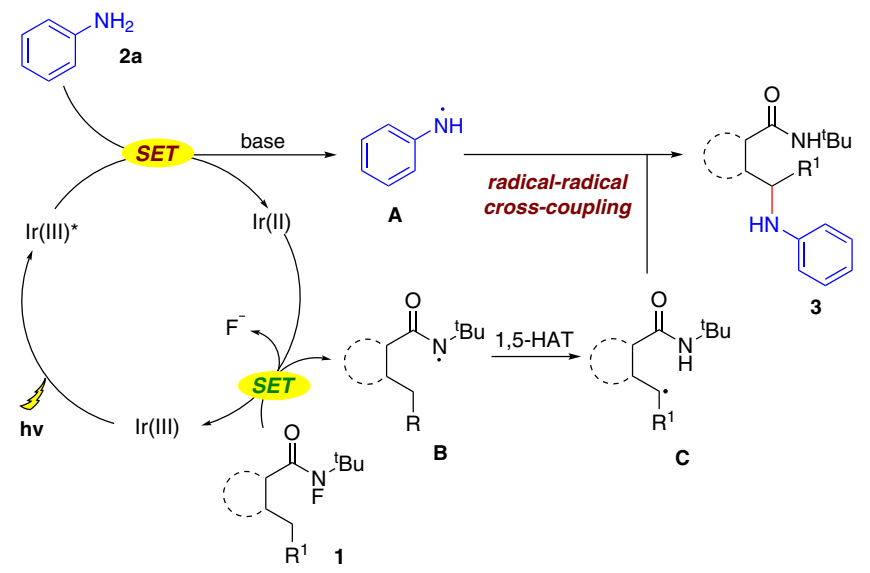

Fig. 9 Proposed mechanism. Proposed mechanism for photoinduced C $\left(\mathrm{sp}^{3}\right)-\mathrm{N}$ coupling reactions.

Mechanistic investigations. In order to gain some mechanistic insight of this $\mathrm{sp}^{3} \mathrm{C}-\mathrm{N}$ coupling reaction, several control experiments were carried out (Fig. 8). The reaction was completely shut down by 2,2,6,6-tetramethylpiperidin-1-oxyl (TEMPO, Equation (1)). Furthermore, when the radical scavenger ethane-1,1-diyldibenzene was added to the reaction, the corresponding threecomponent-type product $\mathbf{1 3}$ was obtained in $45 \%$ yield (Equation (2)). When 1a and aniline (2a) were used as substrates, the desired product 3a was isolated in $73 \%$ yield. Notably, the homo-coupling product 14 was also obtained in the reaction system with $5 \%$ yield (Equation (3)). These results suggested that a) the radical pathway might be involved in the reaction; b) the HLF-type 1,5-HAT proceeded in the system and formed the $\mathrm{C}$-center radical; c) aryl amine possibly converted to the corresponding $\mathrm{N}$-center radical under standard conditions; d) the radical-radical coupling route might be responsible for this $\mathrm{sp}^{3} \mathrm{C}-\mathrm{N}$ bond formation reaction. We also tried this reaction under oxidative conditions. In the presence of $\mathrm{N}$-fluorobenzenesulfonimide (NFSI, 3 equiv) ${ }^{43,44}$ or [bis(trifluoroacetoxy)iodo]benzene (PIFA, 3 equiv $)^{57}$, the un-fluoride amide substrate $\mathbf{1 5}$ failed to produce the amination product under standard conditions (Equation (4)). In addition, the $\mathrm{N}$-chloroamide could also give the desired product with modest yield (Equation (5)). These results indicated that the preactivation of the substrates is crucial to this coupling reaction. In our initial hypothesis, the step that aryl amine converts to the corresponding $\mathrm{N}$-center radical was crucial for this transformation. To verify this hypothesis, emission quenching and electron paramagnetic resonance experiments have been conducted, and the results indicated that the radical species was generated in the system (Equation (6)), see the Supplementary Information for details). The Stern-Volmer plot showed strong quenching of Ir $(\text { ppy })_{2}(\mathrm{dtbpy}) \mathrm{PF}_{6}\left(E_{1 / 2} * \mathrm{III} / \mathrm{II}=+0.66 \mathrm{~V}\right.$ vs. SCE $)$ by $\mathrm{PhNH}_{2}(\mathbf{2 a})$ $\left(E_{1 / 2}{ }^{\text {red }}=+0.94 \mathrm{~V}\right.$ vs. SCE), favoring a reductive quenching cycle. These evidences indicated that the excited-state $\operatorname{Ir}(\mathrm{ppy})_{2}(\mathrm{dtbpy})$ $\mathrm{PF}_{6}$ might undergo a SET process that furnished the formation of $\mathrm{N}_{\text {aryl-center radical. }}$

Proposed mechanism. Based on our investigations and previous reports, a plausible mechanism is proposed in Fig. 9 (see the Supplementary Information for details). The reaction starts with the oxidation of 2 by the excited-state $\operatorname{Ir}(\mathrm{III})^{*}$ in the presence of a base, yielding amine radical $\mathbf{A}$ and $\operatorname{Ir}(\mathrm{II})$. Then, the Ir (II) $\left(E_{1 / 2}{ }^{\text {III/II }}=-1.51 \mathrm{~V} \text { vs. SCE }\right)^{58,59}$ species facilitated the second SET process of substrate $\mathbf{1}\left(E_{\mathrm{p}}{ }^{0 /-1}(\mathbf{1 a})=-0.84 \mathrm{~V}\right.$ vs. SCE in $\mathrm{MeCN}$ ) to generate the amidyl radical $\mathbf{B}$. The subsequent 1,5-HAT formed the radical intermediate $\mathbf{C}$ along with the oxidation of $\operatorname{Ir}(\mathrm{II})$ to $\operatorname{Ir}(\mathrm{III})$ to close the catalytic cycle. Finally, the radical-radical cross-coupling between $\mathrm{N}$-center radical $\mathbf{A}$ and $\mathrm{C}$-center radical intermediate $\mathbf{C}$ was proposed to provide the $\mathrm{sp}^{3} \mathrm{C}-\mathrm{N}$ cross-coupling product 3 .

\section{Discussion}

In conclusion, we disclosed a visible-light-promoted $\mathrm{C}-\mathrm{N}$-radical cross-coupling to realize the regioselective amination of remote $\mathrm{C}$ $\left(\mathrm{sp}^{3}\right)-\mathrm{H}$ bonds. In the reactions, the $\mathrm{N}$-center radicals were directly generated from aryl amines under visible-light irradiation. Using the photoinduced HLF-type 1,5-HAT strategy, the regioselective $\mathrm{C}\left(\mathrm{sp}^{3}\right)-\mathrm{C}\left(\mathrm{sp}^{3}\right)$ cross-coupling was also achieved by using alkyl Hantzsch esters (or nitrile) as alkylation reagents. Notably, the $\alpha-C\left(\mathrm{sp}^{3}\right)-\mathrm{H}$ of tertiary amines was directly alkylated to form the $\mathrm{C}\left(\mathrm{sp}^{3}\right)-\mathrm{C}\left(\mathrm{sp}^{3}\right)$ bonds via $\mathrm{C}\left(\mathrm{sp}^{3}\right)-\mathrm{H}-\mathrm{C}\left(\mathrm{sp}^{3}\right)-\mathrm{H}$ crosscoupling. All the reactions proceeded at room temperature without the assistance of external oxidants.

\section{Methods}

General procedure for condition A. In a dry 10 -ml glass test tube, substrate $\mathrm{N}$ fluoroamides $(0.2 \mathrm{mmol})$, amine $\left(0.6 \mathrm{mmol}, 3\right.$ equiv), $\operatorname{Ir}(\mathrm{ppy})_{2}(\mathrm{dtbpy}) \mathrm{PF}_{6}(1 \mathrm{~mol} \%)$, and $\mathrm{K}_{2} \mathrm{CO}_{3}(0.6 \mathrm{mmol}$, 3 equiv) were dissolved in DMF $(2.0 \mathrm{~mL})$ under $\mathrm{Ar}$ atmosphere. The glass test tube was then transferred to a $24-\mathrm{W}$ violet-light photoreactor, where it was irradiated for $12 \mathrm{~h}$. The residue was added water $(10 \mathrm{~mL})$ and extracted with ethyl acetate $(5 \mathrm{~mL} \times 3)$. The combined organic phase was dried over $\mathrm{Na}_{2} \mathrm{SO}_{4}$. The resulting crude residue was purified via column chromatography on silica gel to afford the desired products.

General procedure for condition B. In a dry $10-\mathrm{ml}$ glass test tube, substrate $\mathrm{N}$ fluoroamides $(0.2 \mathrm{mmol})$, Hantzsch esters or Hantzsch nitrile $(0.6 \mathrm{mmol}, 3$ equiv), $\operatorname{Ir}(\text { ppy })_{2}(\mathrm{dtbpy}) \mathrm{PF}_{6}(1 \mathrm{~mol} \%)$, and $\mathrm{MeOK}(0.5 \mathrm{mmol}, 2.5$ equiv) were dissolved in DCM $(2.0 \mathrm{~mL})$ under Ar atmosphere. The glass test tube was then transferred to a 18 -W blue LED photoreactor, where it was irradiated for $12 \mathrm{~h}$. The residue was added water $(10 \mathrm{~mL})$ and extracted with DCM $(5 \mathrm{~mL} \times 3)$. The combined organic phase was dried over $\mathrm{Na}_{2} \mathrm{SO}_{4}$. The resulting crude residue was purified via column chromatography on silica gel to afford the desired products.

\section{Data availability}

The authors declare that the data supporting the findings of this study are available within the article and its Supplementary Information. Data are also available from the corresponding author on request.

Received: 23 October 2019; Accepted: 21 February 2020; Published online: 19 March 2020

\section{References}

1. Ricci, A. Amino Group Chemistry: From Synthesis to the Life Sciences. (WileyVCH, Weinheim, Germany, 2008)

2. Lawrence, S. A. Amines: Synthesis, Properties and Applications. (Cambridge University Press, Cambridge, 2004).

3. Ruiz-Castillo, P. \& Buchwald, S. L. Applications of palladium-catalyzed C-N cross-coupling reactions. Chem. Rev. 116, 12564-12649 (2016).

4. Sambiagio, C., Marsden, S. P., Blacker, A. J. \& McGowan, P. C. Copper catalysed Ullmann type chemistry: from mechanistic aspects to modern development. Chem. Soc. Rev. 43, 3525-3550 (2014).

5. Qiao, J. X. \& Lam, P. Y. S. Copper-promoted carbon-heteroatom bond cross-coupling with boronic acids and derivatives. Synthesis 6, 829-856 (2011).

6. Choi, J. \& Fu, G. C. Transition metal-catalyzed alkyl-alkyl bond formation: another dimension in cross-coupling chemistry. Science 356, 152-160 (2017).

7. $\mathrm{Hu}, \mathrm{X}$. Nickel-catalyzed cross coupling of non-activated alkyl halides: a mechanistic perspective. Chem. Sci. 2, 1867-1886 (2011).

8. Tasker, S. Z., Standley, E. A. \& Jamison, T. F. Recent advances in homogeneous nickel catalysis. Nature 509, 299-309 (2014).

9. Do, H.-Q., Bachman, S., Bissember, A. C., Peters, J. C. \& Fu, G. C. Photoinduced, copper-catalyzed alkylation of amides with unactivated secondary alkyl halides at room temperature. J. Am. Chem. Soc. 136 2162-2167 (2014). 
10. Zhao, W., Wurz, R. P., Peters, J. C. \& Fu, G. C. Photoinduced, coppercatalyzed decarboxylative $\mathrm{C}-\mathrm{N}$ coupling to generate protected amines: an alternative to the Curtius rearrangement. J. Am. Chem. Soc. 139, 12153-12156 (2017).

11. Corcoran, E. B. et al. Aryl amination using ligand-free $\mathrm{Ni}(\mathrm{II})$ salts and photoredox catalysis. Science 353, 279-283 (2016).

12. Mao, R., Frey, A., Balon, J. \& Hu, X. Decarboxylative C( $\left.\mathrm{sp}^{3}\right)-\mathrm{N}$ crosscoupling via synergetic photoredox and copper catalysis. Nat. Catal. 1, 120-126 (2018).

13. Kemper, J. \& Studer, A. Stable reagents for the generation of N-centered radicals: hydroamination of norbornene. Angew. Chem. Int. Ed. 44, 4914-4917 (2005).

14. Guin, J., Mück-Lichtenfeld, C., Grimme, S. \& Studer, A. Radical transfer hydroamination with aminated cyclohexadienes using polarity reversal catalysis: scope and limitations. J. Am. Chem. Soc. 129, 4498-4503 (2007)

15. Guin, J., Frohlich, R. \& Studer, A. Thiol-catalyzed stereoselective transfer hydroamination of olefins with $\mathrm{N}$-aminated dihydropyridines. Angew. Chem. Int. Ed. 47, 779-782 (2008).

16. Cecere, G., König, C. M., Alleva, J. L. \& MacMillan, D. W. C. Enantioselective direct $\alpha$-amination of aldehydes via a photoredox mechanism: a strategy for asymmetric amine fragment coupling. J. Am. Chem. Soc. 135, 11521-11524 (2013).

17. $\mathrm{Hu}, \mathrm{X}$.-Q. et al. Photocatalytic generation of $\mathrm{N}$-centered hydrazonyl radicals: a strategy for hydroamination of $\beta, \gamma$-unsaturated hydrazones. Angew. Chem. Int. Ed. 53, 12163-12167 (2014).

18. Wappes, E. A., Nakafuku, K. M. \& Nagib, D. A. Directed $\beta$ C-H amination of alcohols via radical relay chaperones. J. Am. Chem. Soc. 139, 10204-10207 (2017).

19. Stateman, L. M., Wappes, E. A., Nakafuku, K. M., Edwards, K. M. \& Nagib, D. A. Catalytic $\beta \mathrm{C}-\mathrm{H}$ amination via an imidate radical relay. Chem. Sci. 10, 2693-2699 (2019).

20. Nakafuku, K. M., Fosu, S. C. \& Nagib, D. A. Catalytic alkene difunctionalization via imidate radicals. J. Am. Chem. Soc. 140, 11202-11205 (2018).

21. Hofman, A. W. Ueber die einwirkung des broms in alkalischer Lösung auf die amine. Ber. Dtsch. Chem. Ges. 16, 558-560 (1883).

22. Löffler, K. \& Freytag, C. Über das $\omega$-Oxy- $\alpha$-propyl-piperidin und eine neue synthese des piperolidins ( $\delta$-coniceins). Ber. Dtsch. Chem. Ges. 42, 3427-3431 (1909).

23. Hlrnández, R., Rivera, A., Salazar, J. A. \& Suárez, E. Nitroamine radicals as intermediates in the functionalization of non-activated carbon atoms. J. Chem. Soc. Chem. Commun. 20, 958-959 (1980).

24. Betancor, C., Concepción, J. I., Hernández, R., Salazar, J. A. \& Suárez, E. Intramolecular functionalization of phosphoramidate radicals. Synthesis of 1,4-Epimine compounds. J. Org. Chem. 48, 4430-4432 (1983).

25. DeArmas, P. et al. Synthesis of 1,4-epimine compounds. Iodosobenzene diacetate, an efficient for neutral nitrogen radical generation. Tetrahedron Lett. 26, 2493-2496 (1985).

26. Paz, N. R. et al. Chemoselective intramolecular functionalization of methyl groups in nonconstrained molecules promoted by $\mathrm{N}$-iodosulfonamides. Org. Lett. 17, 2370-2373 (2015).

27. Richers, J., Heilmann, M., Drees, M. \& Tiefenbacher, K. Synthesis of lactones via $\mathrm{C}-\mathrm{H}$ functionalization of nonactivated $\mathrm{C}\left(\mathrm{sp}^{3}\right)-\mathrm{H}$ bonds. Org. Lett. 18, 6472-6475 (2016).

28. Martínez, C. \& Muñiz, K. An iodine-catalyzed Hofmann-Löffler reaction. Angew. Chem. Int. Ed. 54, 8287-8291 (2015).

29. Wappes, E. A., Fosu, S. C., Chopko, T. C. \& Nagib, D. A. Triiodide-mediated d-amination of secondary C-H bonds. Angew. Chem. Int. Ed. 55, 9974-9978 (2016).

30. Reddy, E. R., Reddy, B. V. S. \& Corry, E. G. Efficient method for selective introduction of substituents as $\mathrm{C}(5)$ of isoleucine and other $\alpha$-amino acids. Org. Lett. 8, 2819-2821 (2006).

31. Richers, J., Heilmann, M., Drees, M. \& Tiefenbacher, K. Synthesis of lactones via $\mathrm{C}-\mathrm{H}$ functionalization of nonactivated $\mathrm{C}\left(\mathrm{sp}^{3}\right)-\mathrm{H}$ bonds. Org. Lett. 18, 6472-6475 (2016).

32. Liu, T., Myers, M. C. \& Yu, J.-Q. Copper-catalyzed bromination of C( $\left.\mathrm{sp}^{3}\right)-\mathrm{H}$ Bonds distal to functional groups. Angew. Chem. Int. Ed. 56, 306-309 (2017).

33. Groendyke, B. J., AbuSalim, D. I. \& Cook, S. P. Iron-catalyzed, fluoroamidedirected C-H fluorination. J. Am. Chem. Soc. 138, 12771-12774 (2016).

34. Choi, G. J., Zhu, Q., Miller, D. C., Gu, C. J. \& Knowles, R. R. Catalytic alkylation of remote $\mathrm{C}-\mathrm{H}$ bonds enabled by proton-coupled electron transfer. Nature 539, 268-271 (2016).

35. Chu, J. C. K. \& Rovis, T. Amide-directed photoredox-catalysed C-C bond formation at unactivated $\mathrm{sp}^{3} \mathrm{C}-\mathrm{H}$ bonds. Nature 539, 272-275 (2016).

36. Shu, W., Genoux, A., Li, Z. \& Nevado, C. $\gamma$-Functionalizations of amines through visible-light-mediated, redox-neutral $\mathrm{C}-\mathrm{C}$ bond cleavage. Angew. Chem. Int. Ed. 56, 10521-10524 (2017)
37. Wu, K., Wang, L., Colón-Rodríguez, S., Flechsig, G.-U. \& Wang, T. Amidyl radical directed remote allylation of unactivated $\mathrm{sp}^{3} \mathrm{C}-\mathrm{H}$ bonds by organic photoredox catalysis. Angew. Chem. Int. Ed. 58, 1774-1778 (2019).

38. Bao, X., Wang, Q. \& Zhu, J. Copper-catalyzed remote $\mathrm{C}\left(\mathrm{sp}^{3}\right)-\mathrm{H}$ azidation and oxidative trifluoromethylation of benzohydrazides. Nat. Commun. 10, 1-7 (2019)

39. Xia, Y., Wang, L. \& Studer, A. Site-selective remote radical C-H functionalization of unactivated $\mathrm{C}-\mathrm{H}$ bonds in amides using sulfone reagents. Angew. Chem. Int. Ed. 57, 12940-12944 (2018).

40. Zhang, H., Zhou, Y., Tian, P. \& Jiang, C. Copper-catalyzed amide radicaldirected cyanation of unactivated Csp ${ }^{3}-\mathrm{H}$ bonds. Org. Lett. 21, 1921-1925 (2019).

41. Morcillo, S. P. et al. Photoinduced remote functionalization of amides and amines using electrophilic nitrogen radicals. Angew. Chem. Int. Ed. 57, 12945-12949 (2018).

42. Liu, Z. et al. Copper-catalyzed remote $\mathrm{C}\left(\mathrm{sp}^{3}\right)-\mathrm{H}$ trifluoromethylation of carboxamides and sulfonamides. Angew. Chem. Int. Ed. 58, 2510-2513 (2019).

43. Li, Z., Wang, Q. \& Zhu, J. Copper-catalyzed arylation of remote C( $\left.\mathrm{sp}^{3}\right)-\mathrm{H}$ bonds in carboxamides and sulfonamides. Angew. Chem. Int. Ed. 57, 13288-13292 (2018).

44. Zhang, Z., Stateman, L. M. \& Nagib, D. A. $\delta$ C-H (hetero)arylation via Cucatalyzed radical relay. Chem. Sci. 10, 1207-1211 (2019).

45. Thullen, S. M., Treacy, S. M. \& Rovis, T. Regioselective alkylative crosscoupling of remote unactivated $\mathrm{C}\left(\mathrm{sp}^{3}\right)-\mathrm{H}$ bonds. J. Am. Chem. Soc. 141, 14062-14067 (2019).

46. Yoo, W.-J. \& Li, C.-J. Highly efficient oxidative amidation of aldehydes with amine hydrochloride salts. J. Am. Chem. Soc. 128, 13064-13065 (2006).

47. $\mathrm{Li}, \mathrm{Z}$. \& Li, C.-J. CuBr-catalyzed direct indolation of tetrahydroisoquinolines via cross-dehydrogenative coupling between $\mathrm{sp}^{3} \mathrm{C}-\mathrm{H}$ and $\mathrm{sp}^{2} \mathrm{C}-\mathrm{H}$ Bonds. J. Am. Chem. Soc. 127, 6968-6969 (2005).

48. Li, Z. \& Li, C.-J. Highly efficient copper-catalyzed nitro-Mannich type reaction: cross-dehydrogenative-coupling between $\mathrm{sp}^{3} \mathrm{C}-\mathrm{H}$ bond and $\mathrm{sp}^{3} \mathrm{C}$ -H bond. J. Am. Chem. Soc. 127, 3672-3673 (2005).

49. $\mathrm{Li}, \mathrm{Z}$. \& Li, C.-J. CuBr-catalyzed efficient alkynylation of $\mathrm{sp}^{3} \mathrm{C}-\mathrm{H}$ bonds adjacent to a nitrogen atom. J. Am. Chem. Soc. 126, 11810-11811 (2004).

50. Le, C., Liang, Y., Evans, R. W., Li, X. \& MacMillan, D. W. C. Selective $\mathrm{sp}^{3}$ C-H alkylation via polarity-match-based cross-coupling. Nature 547, 79-83 (2017).

51. Zhou, W.-J. et al. Visible-light-driven palladium-catalyzed radical alkylation of $\mathrm{C}-\mathrm{H}$ bonds with unactivated alkyl bromides. Angew. Chem. Int. Ed. 56, 15683-15687 (2017).

52. Li, G. et al. Alkyl transfer from C-C cleavage. Angew. Chem. Int. Ed. 52, 8432-8436 (2013).

53. Leeuwen, T. V., Buzzetti, L., Perego, L. A. \& Melchiorre, P. A redox-active nickel complex that acts as an electron mediator in photochemical Giese reactions. Angew. Chem. Int. Ed. 58, 4953-4957 (2019).

54. Chen, W. et al. Building congested ketone: substituted Hantzsch ester and nitrile as alkylation reagents in photoredox catalysis. J. Am. Chem. Soc. 138, 12312-12315 (2016)

55. Nakajima, K., Nojima, S. \& Nishibayashi, Y. Nickel- and photoredox-catalyzed cross-coupling reactions of aryl halides with 4-alkyl-1,4-dihydropyridines as formal nucleophilic alkylation reagents. Angew. Chem. Int. Ed. 55, 14106-14110 (2016).

56. Nechab, M., Mondal, S. \& Bertrand, M. P. 1,n-Hydrogen-atom transfer (HAT) reactions in which $\mathrm{n} \neq 5$ : an updated inventory. Chem. Eur. J. 20, 16034-16059 (2014)

57. Tang, N., Wu, X. \& Zhu, C. Practical, metal-free remote heteroarylation of amides via unactivated $\mathrm{C}\left(\mathrm{sp}^{3}\right)-\mathrm{H}$ bond functionalization. Chem. Sci. 10, 6915-6919 (2019)

58. Lowry, M. S. et al. Single-layer electroluminescent devices and photoinduced hydrogen production from an ionic iridium(III) complex. Chem. Mater. 17, 5712-5719 (2005)

59. Slinker, J. D. et al. Efficient yellow electroluminescence from a single layer of a cyclometalated iridium complex. J. Am. Chem. Soc. 126, 2763-2767 (2004).

\section{Acknowledgements}

We are grateful for the grants from the NSFC (21971098) and the Fundamental Research Funds for the Central Universities (lzujbky-2018-k9). The authors also thank Prof. Rui Wang, Prof. Yawen Wang, Prof. Pinxian Xi, and Prof. Qiang Liu at Lanzhou University for helpful discussion and technical assistance.

\section{Author contributions}

Z.X. conceived and designed the research. Q.G., Q.P., H.C., Y.H., and S.W. performed the research. Q.G. and Z.X. cowrote the paper.

\section{Competing interests}

The authors declare no competing interests. 


\section{Additional information}

Supplementary information is available for this paper at https://doi.org/10.1038/s41467020-15167-2.

Correspondence and requests for materials should be addressed to Z.X.

Peer review information Nature Communications thanks the anonymous reviewer(s) for their contribution to the peer review of this work.

Reprints and permission information is available at http://www.nature.com/reprints

Publisher's note Springer Nature remains neutral with regard to jurisdictional claims in published maps and institutional affiliations. (c) Open Access This article is licensed under a Creative Commons Attribution 4.0 International License, which permits use, sharing, adaptation, distribution and reproduction in any medium or format, as long as you give appropriate credit to the original author(s) and the source, provide a link to the Creative Commons license, and indicate if changes were made. The images or other third party material in this article are included in the article's Creative Commons license, unless indicated otherwise in a credit line to the material. If material is not included in the article's Creative Commons license and your intended use is not permitted by statutory regulation or exceeds the permitted use, you will need to obtain permission directly from the copyright holder. To view a copy of this license, visit http://creativecommons.org/ licenses/by/4.0/.

(C) The Author(s) 2020 